\title{
Produção e caracterização física e química do bioetanol a partir de resíduos de biomassa da banana Musa acuminata, laranja Citrus sinensis e maracujá Passiflora edulis f. flavicarpa
}

\section{Lisa Sousa Cerqueira Santos ${ }^{1}$, Paula de Sousa Cunha Mota $^{1}$, Sandini da Silva Rebouças ${ }^{1}$, Madson Moreira Nascimento $^{2}$ e Aldenor Gomes Santos ${ }^{3}$}

${ }^{1}$ Centro Universitário Jorge Amado. Curso de Engenharia Química. Campus Paralela. Paralela. Salvador-BA, Brasil (CEP 41745-130).

${ }^{2}$ Universidade Federal da Bahia. Centro Interdisciplinas de Energia e Ambiente. Campus de Ondina. Salvador-BA, Brasil (CEP 40170-115).

${ }^{3}$ Centro Universitário Jorge Amado. Laboratório de Química Analítica e Ambiental. Campus Paralela. Salvador-BA, Brasil (CEP 41745-130). *E-mail: aldenor.santos@unijorge.edu.br.

Resumo. A transformação de biomassas agroindustriais em bioetanol, além de ser uma rota alternativa para produção de combustíveis, traz uma valorização dos rejeitos e resíduos provenientes do processo. Este artigo relata a produção e caracterização física e química do bioetanol a partir do resíduo de biomassa mista, composta por cascas da banana Musa acuminata, da laranja Citrus sinensis e do maracujá Passiflora edulis f. flavicarpa. As amostras de mostos fermentados, B1 e B2, foram destilados após 24 h e 96 h, obtendo, respectivamente, 18,5\% e $11 \%$ de rendimento alcoólico. 0 bioetanol produzido foi caracterizado através de paramentos físicos e químicos, como $\mathrm{pH}$, condutividade elétrica, teor alcoólico, índice de acidez e sólidos totais de acordo com a Agência Nacional do Petróleo (ANP). Uma análise empregando a técnica de headspace acoplada a um cromatógrafo a gás com detector de massas (HS/GC-MS) foi realizada para identificação do etanol nas amostras. Os resultados encontrados nas análises de B1 e B2 foram, respectivamente, $\mathrm{pH}$ 3,75 e 3,64, índice de acidez 56,21 e 56,21 mg/L, condutividade 81,4 e $219 \mu \mathrm{S} / \mathrm{cm}$, teor alcoólico 15,60 e 13,04 v/v e sólidos totais 0,0543 e $0,1465 \mathrm{mg} / \mathrm{L}$. Os estudos das propriedades e características demonstraram a viabilidade de produzir etanol a partir de biomassa das frutas, sendo uma forma de agregar valor a estes resíduos.

Palavras-chave: Biomassa; Bioetanol; Fermentação alcoólica; Parâmetros físicos e químicos.

Abstract. Production and physico-chemical characterization of bioethanol from biomass residues of banana Musa acuminata,
Recebido

$11 / 02 / 2020$

Aceito

13/06/2020

Disponível on line 15/06/2020

Publicado

$31 / 08 / 2020$

\section{Acesso aberto}

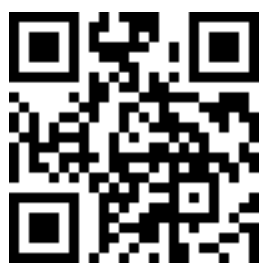

ORCID

0000-0001-5768-6689 Lisa Sousa Cerqueira Santos

D) 0000-0002-9214-0267 Paula de Sousa Cunha Mota 
orange Citrus sinensis and passion fruit Passiflora edulis $f$. flavicarpa. The transformation of agroindustrial biomasses into bioethanol, besides being an alternative route for fuel production, brings an appreciation of the waste and residues from this process. This paper reports the obtaining and physic-chemical characterization of bioethanol produced from mixed biomass residue, composed of banana, orange and passion fruit peels. The fermented musts, called B1 and B2, were distilled after $24 \mathrm{~h}$ and $96 \mathrm{~h}$, obtaining, respectively, $18.5 \%$ and $11 \%$ of alcoholic yield. The quality of the bioethanol produced was assessed through the physicochemical parameters such as $\mathrm{pH}$, electrical conductivity, alcohol content, acidity index and total solids according to the National Petroleum Agency (ANP). The results found in B1 and B2 samples were, respectively, $\mathrm{pH} 3.75$ and 3.64, acidity index 56.21 and $56.21 \mathrm{mg} / \mathrm{L}$, conductivity 81.4 and $219 \mu \mathrm{S} / \mathrm{cm}$, alcohol content 15.60 and $13.04(\mathrm{v} / \mathrm{v})$ and total solids 0.0543 and 0.1465 $\mathrm{mg} / \mathrm{L}$. The study properties and characteristics demonstrated the viability of producing ethanol from fruit biomass, being a way to add value to these residues.

Keywords: Biomass; Bioethanol; Alcoholic fermentation; Physico-chemical dressing.
D) $0000-0001-6642-7830$

Sandini da Silva

Rebouças

D) 0000-0003-4405-6519

Madson Moreira

Nascimento

D) 0000-0002-5472-4026

Aldenor Gomes Santos

\section{Introdução}

A adoção de energia alternativa vem sendo buscada desde os anos 1970, quando a crise do petróleo levou diversos países a procurar a segurança no fornecimento de energia e a redução da dependência da importação de combustíveis. Recentemente, as preocupações ambientais se tornaram o maior motor para a busca de alternativas mais limpas de produção de energia (Simas e Pacca, 2013).

A biomassa é considerada uma das principais alternativas para a diversificação da matriz energética e a consequente redução da dependência dos combustíveis fósseis, além de uma das fontes para produção de energia com maior potencial de crescimento. Dela é possível obter energia elétrica e biocombustíveis, como o etanol, cujo consumo é crescente em substituição dos derivados de petróleo como o óleo diesel e a gasolina (Smuga-Kogut, et al., 2019; Chohan, et al., 2020). Uma vantagem importante dos biocombustíveis, como o etanol, sobre os combustíveis derivados do petróleo é que (1) contribuem para a mitigação das emissões de GEE, (2) fornecem uma fonte de energia limpa e sustentável, (3) são biodegradáveis e contribuem para a sustentabilidade, e (4) aumentam a renda agrícola nos países em desenvolvimento (Zouhair et al., 2020).

0 bioetanol é um combustível alternativo promissor para substituir os combustíveis fósseis e seus derivados. A produção de etanol a partir de resíduos de alimentos contendo carboidratos pode ser aceita como um processo econômico para seu uso, uma vez que é usado como combustível único ou misturado à gasolina. Resíduos ricos em açúcar são substratos disponíveis para a produção de bioetanol na indústria de processamento de frutas, como suco de frutas, bolachas e gomas (Erman et al., 2017).

Os rejeitos e os resíduos agrícolas, em sua maioria contendo materiais lignocelulósicos, ocupam lugar de destaque entre a biomassa disponível, sobretudo em função da sua abundância e do caráter renovável. A biomassa lignocelulósica é composta, basicamente, por $40 \%$ a $60 \%$ de celulose, $20 \%$ a $40 \%$ de hemicelulose e $15 \%$ a $25 \%$ de 
lignina (Moreira, 2005; Souza et al., 2012), o que torna a produção de biocombustível a partir desta matriz uma boa fonte alternativa e renovável de energia (Schulz, 2010).

Segundo Aquarone et al. (2001), qualquer produto que contenha açúcar ou outro carboidrato pode ser matéria-prima para a obtenção de etanol. Entretanto, deve-se analisar a sua viabilidade com o volume de produção, rendimento industrial e custo de fabricação. A biomassa rejeitada das frutas pode ser uma boa fonte de matéria-prima para o etanol de segunda geração. Este é obtido a partir da utilização de enzimas para realizar a hidrólise enzimática/sacarificação, que é uma reação química onde a enzima quebra as moléculas de açucares em moléculas menores utilizando a água (Ogeda et al., 2010), onde o amido é convertido em açucares fermentáveis. Este processo enzimático auxilia o processo fermentativo, realizado pelas leveduras, que é a conversão dos açucares quebrados em etanol (Barros, 2010).

A fruticultura é o setor de maior destaque na agricultura brasileira. 0 país dispõe de uma vasta variedade de culturas produzidas em seu território e em todos os climas. 0 Brasil é o terceiro maior produtor frutífero do mundo, sendo responsável pela produção de 43,6 milhões de toneladas no ano de 2013. Deste total de frutas produzidas pelo país estima-se que, aproximadamente, $55 \%$ é direcionado para indústria de processamento de frutas, e o restante para seu consumo in natura (SEBRAE, 2015). Como consequência do volume de frutas que são processadas, existem os resíduos provenientes desta atividade que, em geral, não são aproveitados pelas empresas. Nas indústrias de polpa de frutas, os resíduos das frutas são obtidos durante o processamento da extração de polpa de frutas e são compostos, na maioria das vezes, por casca de frutas, pedras ou caroços e sementes (Matias et.al., 2005).

A laranja pode ser utilizada integralmente, pois, após a extração do suco, geram-se $50 \%$ de um resíduo constituído de casca, semente e membranas, que são desidratados e comercializados como constituintes para produção de ração animal (Lohrasbi et al., 2010; Cypriano, 2015). A casca da laranja possui açúcares solúveis, como glicose, frutose e sacarose, e polissacarídeos insolúveis, presentes na parede celular da casca da fruta, como pectina, celulose e hemicelulose, e uma pequena quantidade de lignina (Grohamann et al., 1995).

A banana Musa spp. é a segunda fruta mais explorada no Brasil, correspondendo $16,2 \%$ do volume total de frutas produzidas. São Paulo é o maior produtor de bananas do país, seguido de Bahia e Minas Gerais (Andrade, 2012). Segundo Fernandes et. al. (2011) e Athayde (2014), em uma empresa de alimentos, para cada tonelada de banana colhida, aproximadamente, 4 toneladas de resíduos lignocelulósicos são gerados constituídos de cascas, engaços, frutos rejeitados, dentre outros. A casca da banana é composta, além de amido, proteínas e gorduras, por açúcares como, glicose, frutose, sacarose, além de ser uma boa fonte de lignina, pectina, celulose e hemicelulose (Mohapatra e Mishra, 2010).

O Brasil é o maior produtor mundial de maracujá, chegando a produzir $330 \mathrm{mil}$ toneladas da fruta. 0 maracujá-amarelo Passiflora edulis f. flavicarpa é o mais cultivado no mundo, e responsável por mais de $95 \%$ da produção do Brasil e utilizados principalmente no preparo de sucos, onde se geram, aproximadamente, 240 mil toneladas de cascas e sementes provenientes do seu processamento. (Silva, 2014; Fraife Filho et al., 2015). As cascas de frutas cítricas, incluindo o maracujá, são compostas do "flavedo" ou epicarpo e do "albedo" ou mesocarpo, facilmente separáveis da polpa, que corresponde à fração comestível do fruto. No flavedo encontram-se substâncias químicas como os carotenóides, vitaminas e óleo essencial. 0 albedo que corresponde à porção esponjosa, branca e aderente à casca, é rico em hemicelulose, celulose, lignina, glicídeos solúveis, substâncias pécticas e compostos fenólicos (Mendonça et al., 2006).

Cypriano (2015) realizou um estudo referente à produção de etanol 2G partir das cascas e bagaços da laranja, utilizando os processos de sacarificação e fermentação. A autora conduziu o estudo tanto para as fermentações com monocultura como para 
co-culturas, onde obteve 6,2 a $37,7 \%$ e 3,0 a $41,6 \%$, respectivamente, de conversão do açúcar contido no mosto. Neste mesmo estudo, a autora, com base em seus resultados de conversão, afirmou que com 8,5 milhões de toneladas de resíduo da laranja pode-se produzir $18,31.10^{6} \mathrm{~L}$ a $140,05.10^{6} \mathrm{~L}$ de etanol em um ano, utilizando-se a fermentação industrial por monocultura e para co-cultura seria de $8,49.10^{6} \mathrm{~L}$ a $174,52.10^{6} \mathrm{~L}$. Schulz (2010) produziu etanol de segunda geração a partir de rejeitos de banana, pelos processos de hidrolise ácida, hidrolise enzimática e fermentação. Os ensaios foram conduzidos em diferentes tempos de fermentação e condições de pressão e temperatura. Assim, de maneira global, obteve uma produção de 7,88 e 7,15 g.L-1 a partir das cascas de banana e 40,0 g.L $\mathrm{L}^{-1}$ a partir da polpa.

O bioetanol produzido a partir de biomassa é um combustível alternativo promissor e tem como objetivo substituir os combustíveis de origem fóssil, trazendo benefícios ao meio ambiente não só pela preservação desses recursos, como também pela redução de gases que causam o efeito estufa. 0 objetivo deste trabalho foi produzir bioetanol, por meio de hidrólise enzimática, fermentação alcoólica e destilação, a partir de resíduo de biomassa mista, composta por cascas de banana (Musa acuminata), laranja (Citrus sinensis) e maracujá (Passiflora edulis f. flavicarpa). 0 bioetanol obtido foi caracterizado por análise de parâmetros físico-químicos de qualidade, como pH, condutividade elétrica (CE), índice de acidez (IA) e sólidos totais (STD). A identificação inequívoca do etanol foi realizada via análise por GC-MS. 0 estudo aplicando a composição da biomassa mista mostrou-se viável para obtenção do bioetanol, sendo uma forma de agregar valor os resíduos de frutas.

\section{Material e métodos}

\section{Preparação e composição da biomassa}

A cascas da banana prata Musa acuminata, laranja Citrus sinensis e maracujá Passiflora edulis f. flavicarpa utilizadas como matérias-primas para composição da biomassa foram obtidas dos resíduos domésticos, coletadas em residências do bairro de São Marcos, no Município de Salvador-BA. As cascas das frutas foram lavadas e em seguida trituradas por 3 min, sem adição de água, em um liquidificado industrial. Após trituradas, foram pesadas $30 \mathrm{~g}$ da casca de banana prata, $10 \mathrm{~g}$ da casca de laranja e $10 \mathrm{~g}$ da casaca de maracujá, totalizando $50 \mathrm{~g}$ de biomassa. Para eliminar impurezas presentes na biomassa, elas foram levadas ao autoclave por $15 \mathrm{~min}$ a $56^{\circ} \mathrm{C}$. Após arrefecerem, atingindo $27^{\circ} \mathrm{C}$, em dois Erlenmeyrs, às biomassas foram adicionados $200 \mathrm{~mL}$ de água destilada.

\section{Obtenção do bioetanol}

A obtenção do bioetanol foi realizada a partir de uma mistura de biomassa processada, contendo $60 \%$ de casca banana prata, $20 \%$ de casca de laranja e $20 \%$ de casaca de maracujá. A composição da biomassa foi colocada em dois Erlenmeyrs, onde foram adicionados $200 \mathrm{~mL}$ de água destilada.

Para a obtenção do mosto alcoólico, fez-se necessário a sacarificação do amido presente na biomassa, para ocorrer à quebra dos açucares não fermentáveis em fermentáveis, facilitado assim à transformação desses açucares em álcool. Neste processo foram adicionadas 12 gotas da enzima Attenuzyme PRO, agindo por $24 \mathrm{~h}$, para garantir a quebra dos açúcares.

No processo de fermentação alcoólica, após as $24 \mathrm{~h}$ de sacarificação, em temperatura de $24{ }^{\circ} \mathrm{C}$, foram adicionadas $5 \mathrm{~g}$ da levedura Red Star - Pasteur Champagne Premier Blanc, às misturas dos Erlenmeyrs. Foram obtidas duas amostras de bioetanol, sendo B1 deixado reagir por $24 \mathrm{~h}$, e B2 por $96 \mathrm{~h}$. Após o período de fermentação, o mosto foi coado e transferido para o balão de fundo redondo para ser destilado. Foram utilizadas duas torres de destilação simples para a obtenção do bioetanol. As duas amostras foram 
destiladas duas vezes para garantir apenas presença de álcool límpido em composição, à temperatura de $90^{\circ} \mathrm{C}$. As etapas e processos para a produção do bioetanol são mostrados de forma geral na Figura 1.
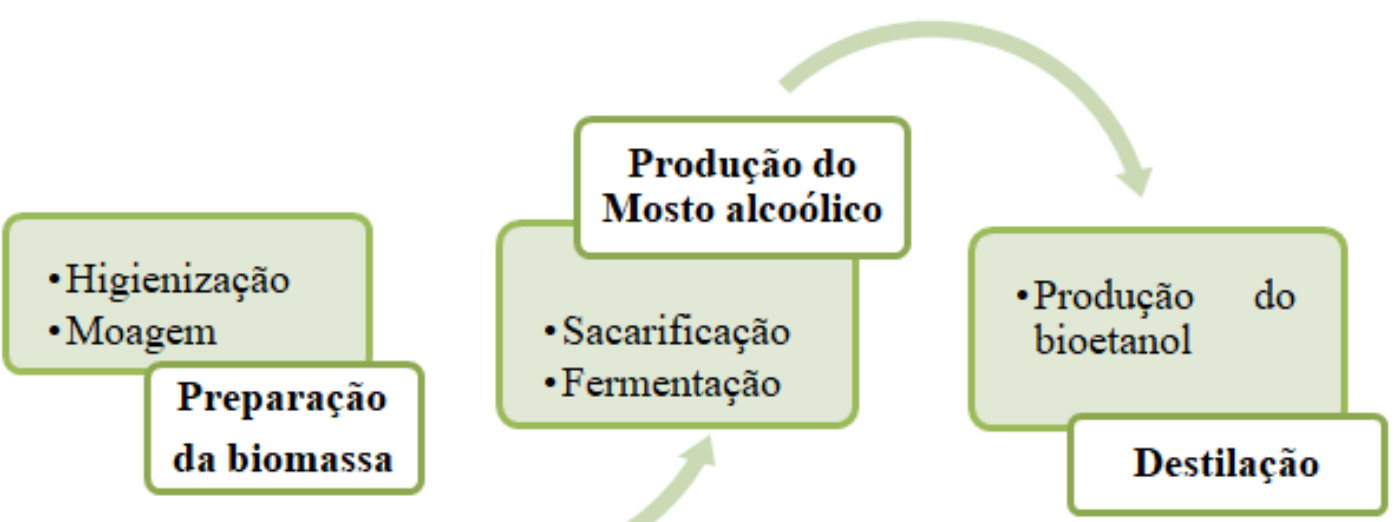

Figura 1. Procedimento para obtenção do bioetanol.

\section{Análises físicas e químicas}

A caracterização física e química do bioetanol produzido foi realizada a partir da análise de alguns parâmetros de qualidade definidos pela Resolução ANP no 7/2011 (ANP, 2011). Foram avaliados o índice de acidez (IA), pH, condutividade elétrica (CE), sólidos totais dissolvidos (STD) e teor alcoólico. Todas as análises foram realizadas em duplicata.

Instrumentos e método analíticos instrumentais foram aplicados para análise de $\mathrm{pH}$, condutividade elétrica (CE) e sólidos totais dissolvidos (STD). $0 \mathrm{pH}$ foi analisado através do método potenciométrico, com um pHmetro digital 0.00-14.00 pH/mv/cda marca Bel Engineering modelo W3B. 0 eletrodo do pHmetro foi introduzido na amostra de bioetanol contidas em um béquer, sob leve agitação para estabilização e leitura do pH e da temperatura. As medidas de condutividade elétrica (CE) e os sólidos totais dissolvidos (STD) foram determinados por um condutivímetro digital da marca OMEGA, modelo CDB 387. Adicionou-se à amostra do bioetanol em um béquer, em seguida foi introduzido o elétrodo e realizado uma leve agitação, estabilizando assim a medida de condutividade elétrica.

O índice de acidez (IA) foi determinação através do método volumétrico quantitativo, utilizando $\mathrm{KOH}$ como padrão e fenolftaleína como indicador. Em um Erlenmeyer foi adicionado $25 \mathrm{~mL}$ da amostra de bioetanol e $1 \mathrm{~mL}$ de fenolftaleína $1 \%$. A amostra foi titulada sob agitação, com a solução de KOH 0,156 mol/L até o ponto final da reação. A análise do branco foi realizada para correção do volume gasto na titulação.

\section{Análises por HS/GC-MS}

A determinação do etanol por headspace e GC-MS foi baseada nas metodologias de Andrade et al. (1998) e Heleno et al. (2010), com algumas modificações. O headspace foi realizado transferindo-se uma alíquota de $1 \mathrm{~mL}$ para vials de vidro de $22 \mathrm{~mL}$ contendo $9 \mathrm{~mL}$ de água ultrapura e $3 \mathrm{~g}$ de $\mathrm{NaCl}$. Em seguida, o vial de vidro foi lacrado com tampa rosqueável de alumínio contendo septo de silicone faceado com teflon. Para volatilização do etanol, o vial de vidro foi transferido para um bloco de aquecimento, sendo mantido por 25 min à temperatura de $70{ }^{\circ} \mathrm{C}$. Através de uma seringa de $2,5 \mathrm{~mL}$, gastight (Hamilton) 
para injeção de vapores, $250 \mu \mathrm{L}$ da fase vapor (headspace) foi recolhido à meia altura entre a tampa do frasco e a superfície da amostra e injetado no GC-MS. A seringa foi previamente lavada com metanol e aquecida a $150{ }^{\circ} \mathrm{C}$ para evitar o efeito de memória. A fase vapor foi imediatamente amostrada e injetada com a seringa ainda aquecida a $80{ }^{\circ} \mathrm{C}$ para evitar condensação da fase de vapor no seu interior.

As análises foram realizadas em um cromatógrafo a gás (GC) acoplado a um espectrômetro de massa (MS), modelo GCMS-QP2010PLUS (Shimadzu, Japão), equipado com um amostrador automático AOC-5000 e injetor split/splitless, operando em modo splitless a $250{ }^{\circ} \mathrm{C}$, com tempo de amostragem de $0,8 \mathrm{~min}$. A separação cromatográfica foi realizada em uma coluna capilar BP5MS-SGE (crossbond ${ }^{\circledR} \quad 5 \%$ difenil, $95 \%$ dimetilpolisiloxano, $30 \mathrm{~m} \times 0,25 \mathrm{~mm} \times 0,25 \mathrm{~mm}$ ). Durante a análise, hélio ultra-puro $(99,999 \%)$ (White Martins, Brasil) foi utilizado como gás de arraste. A programação da temperatura do forno iniciou-se a $40{ }^{\circ} \mathrm{C}(1 \mathrm{~min})$, subindo de $40-250{ }^{\circ} \mathrm{C}\left(10^{\circ} \mathrm{C} \mathrm{min}^{-1}, 5 \mathrm{~min}\right)$. A temperatura da fonte de íons foi mantida a $250{ }^{\circ} \mathrm{C}$, e a temperatura da linha de transferência GC/MS foi mantida a $250{ }^{\circ} \mathrm{C}$. A análise de espectrômetro de massa foi realizada no modo de impacto eletrônico (EI) $(70 \mathrm{eV})$, em modos de varredura completa de alta velocidade (high-speed full scan).

\section{Resultados e discussão}

\section{massas}

\section{Análise cromatográfica e identificação do etanol por espectrometria de}

As amostras de bioetanol foram analisadas a fim de verificar suas conformidades de acordo com a ANP (Martini et al., 2018). A identificação do etanol produzido foi realizada com base no tempo de retenção e no espectro de massas, adquiridos no modo de varredura (scan) em uma faixa de massas que variou de 45 a 400 a.m.u. em um cromatógrafo a gás (GC) acoplado a um espectrômetro de massas (MS). 0 tempo de retenção do etanol e o espectro de massas obtido na mostra analisada, foram comparados com os obtidos na análise de um padrão de etanol de concentração 800. A Figura 2 apresenta o cromatograma e o espectro de massa obtido na análise da amostra.

No GC-MS utilizado no presente estudo, o pico do bioetanol eluiu no tempo de retenção de $1,70 \mathrm{~min}$, imediatamente no mesmo tempo do padrão etanol injetado (Figura 2). 0 etanol foi identificado e confirmado devido à presença dos íons $\mathrm{m} / \mathrm{z} 45 \mathrm{e} \mathrm{m} / \mathrm{z}$ 46 (Figura 2), principais produtos de fragmentação do etanol. 0 índice de similaridade de acordo com as bibliotecas NIST 08 e NIST 08s (National Institute of Standards and Technology, USA) foi de 99\%, confirmando a presença de etanol nas amostras.

\section{Obtenção e rendimento do bioetanol}

A escolha da matriz de biomassa mista utilizada no presente trabalho baseou-se nos estudos de Joner et al. (2012), onde foram realizados ensaios para obtenção de bioetanol em diferentes composições de biomassa. No estudo, os autores encontraram melhores rendimentos alcoólicos $(\% \mathrm{v} / \mathrm{v})$ para a matriz composta por $60 \%$ de banana, $20 \%$ de maçã e $20 \%$ de laranja, onde o rendimento foi de $56,5 \%$. Diante disto, para este estudo utilizou-se $60 \%$ de cascas de banana prata, $20 \%$ de casca de laranja e $20 \%$ de casca de maracujá, a partir das reações de sacarificação, fermentação alcoólica e destilação.

Os açucares do mosto são essenciais para a produtividade da fermentação alcoólica. No processo de destilação do mosto fermentado, foram obtidos $37 \mathrm{~mL}$ e $22 \mathrm{~mL}$ de bioetanol, B1 e B2, respectivamente. Os volumes de bioetanol obtidos representaram um rendimento alcoólico de 18,5\% e 11\%, considerando o volume do mosto filtrado e o volume de álcool que foi destilado. A amostra B1 apresentou ótimo rendimento para a produção de bioetanol. A amostra B2, que teve um tempo maior de fermentação, $94 \mathrm{~h}$, apresentou um rendimento para de bioetanol abaixo do esperado. 

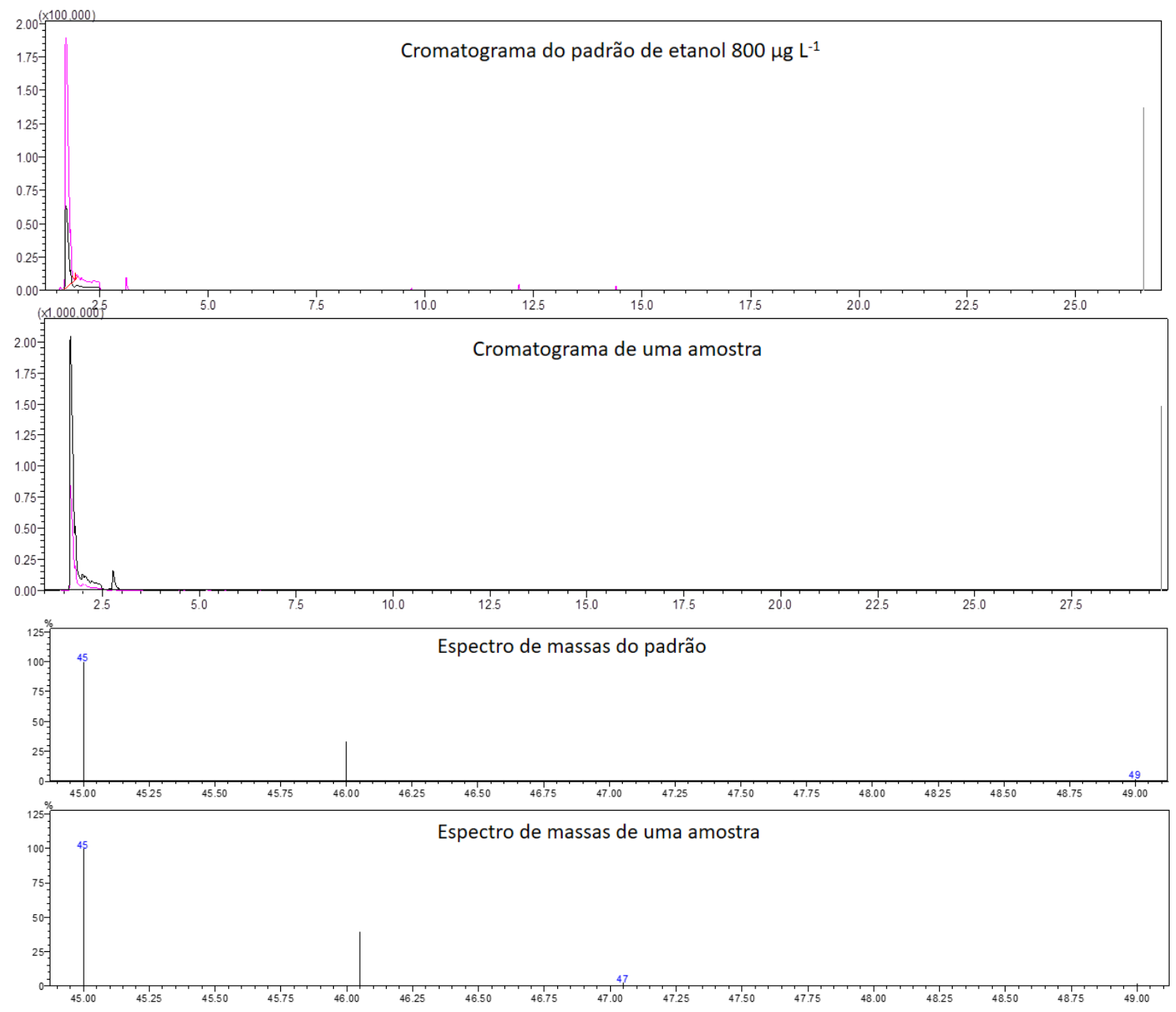

Figura 2. Cromatograma GC-MS-SCAN da amostra de bioetanol analisada.

\section{Caracterização física e química do bioetanol}

As análises dos resultados da caracterização do bioetanol, das amostras B1 e B2, através dos parâmetros físico-químicos que serão apresentados na Tabela 1.

Tabela 1. Resultados dos parâmetros físicos e químicos e comparação com a resolução ANP.

\begin{tabular}{lcc}
\hline & \multicolumn{2}{c}{ Amostras } \\
\cline { 2 - 3 } & B1 & B2 \\
\hline pH & 3,75 & 3,64 \\
Índice de acide $(\mathrm{mg} / \mathrm{L})$ & 56,21 & 56,21 \\
Condutividade $(\mu \mathrm{S} / \mathrm{cm})$ & 81,40 & 219,00 \\
Teor Alcoólico $(\mathrm{v} / \mathrm{v})$ & 15,60 & 13,04 \\
Sólidos totais $(\mathrm{mg} / \mathrm{L})$ & 0,05 & 0,15 \\
\hline
\end{tabular}


A média resultante das análises de B1 e B2 foram, respectivamente, 3.75 e 3.64, resultados semelhantes foram encontrados por Joner et al. (2012). 0 baixo valor do $\mathrm{pH}$ pode ser explicado pela casca da laranja e maracujá serem ácidas, e o não controle do $\mathrm{pH}$ nas etapas de sacarificação e fermentação. Gromahnn et al. (1996) realizou um estudo da fermentação de hidrolisados de casca de laranja, onde neutralizou-se o filtrado da hidrólise enzimática com carbonato de cálcio a fim de ter um pH 5,5 no meio. Segundo a Resolução ANP no 7/2011 (ANP, 2011), o pH do bioetanol deve está na faixa de 6 a 8, ou seja ligeiramente neutro. Um pH ácido ou básico pode acarretar danos ao automóvel, como corrosão de peças metálicas e problemas no transporte e armazenamento (Pereira et al., 2016).

O elevado índice de acidez prejudica a estabilidade térmica do combustível na câmera de combustão, e influencia na hidrólise do combustível e na oxidação causando corrosão dos componentes metálicos do motor (Ramiro, 2013). Os valores encontrados nas amostras B1 e B2, foram de $56.21 \mathrm{mg} / \mathrm{L}$. Os elevados índices podem ser explicados, assim como o pH, pela utilização de cascas de frutas ácidas como a laranja e o maracujá. Joner et al (2012) encontraram valores de acidez titulável (\%) elevados devido à composição de frutas ácidas e semiácidas de sua biomassa. A Resolução ANP no 7/2011 (ANP, 2011), estabelece o teor de acidez máximo de $30 \mathrm{mg} / \mathrm{L}$ (Pereira et al., 2016).

A condutividade elétrica é a capacidade que o combustível apresenta ao dissipar cargas possivelmente geradas durante a transferência do bioetanol. Esta grandeza varia com a concentração total de substâncias ionizadas dissolvidas nos combustíveis, com a mobilidade dos íons, com a sua valência e com as concentrações relativas de cada íon. Uma elevada condutividade elétrica indica a contaminação de substâncias que não deveriam estar presentes no etanol ou estão em quantidade acima do permitido. Caso a condutividade elétrica do produto seja elevada, as cargas são dissipadas rapidamente, evitando o seu acúmulo e minimizando o risco potencial de incêndio durante o manuseio e a distribuição do produto (Cerqueira et al., 2019). A Resolução ANP no 7/2011 (ANP, 2011) estabelece o máximo de $350 \mu \mathrm{S} / \mathrm{m}$ de condutividade elétrica para o bioetanol que deve ser atendida pela produtora e distribuidora do combustível. Os valores obtidos na análise de condutividade de B1 e B2 foram, respectivamente, $81.40 \mu \mathrm{S} / \mathrm{cm}$ e $290.10 \mu \mathrm{S} / \mathrm{cm}$, estando, assim, dentro da exigência estabelecida pela ANP. Essa diferença discrepante entre os valores da condutividade das amostras de B1 e B2 está relacionada à presença de ácidos e outros compostos provenientes das fases de fermentação e destilação, como explica Vanzella (2015).

0 teor alcoólico calculado para as amostras B1 e B2 obteve os resultados, respectivamente, de $15,60 \%$ e $13,04 \% \mathrm{v} / \mathrm{v}$. Estes valores encontram-se abaixo do estabelecido pela Resolução ANP no 7/2011 (ANP, 2011), que esta entre 92,5\% e 95,4\%. Estes resultados estão semelhantes aos encontrados por Joner et al. (2012), que obtiveram valores que variaram entre 0 e 56,5 \%v/v para grau alcoólico do bioetanol, sendo o valor mais baixo para o bioetanol proveniente de matriz $100 \%$ laranja e o valor mais alto para biomassa de $60 \%$ banana, $20 \%$ maçã e $20 \%$ laranja.

Os sólidos totais dissolvidos foi o parâmetro que melhor caracterizou as amostras. Os resultados obtidos para B1 e B2 foram, respectivamente, 0,0543 mg/L e 0,1465 mg/L.

\section{Conclusão}

A produção de bioetanol a partir da hidrólise enzimática das cascas da banana prata, laranja e do maracujá, a partir da enzima comercial Attenuzyme PRO e da levedura Red Star - Pasteur Champagne Premier Blanc, demonstrou viabilidade e eficiência. Esta etapa hidrolítica utilizando apenas água sem introdução de soluções tampão, ácidos ou bases, o que reduz o custo do processo. Observou-se, também, que as fermentações que ocorreram em tempos mais curtos, amostra B1, obteve um rendimento maior que os que 
passaram mais tempo fermentando que foi o caso de B2. 0 pH das amostras (B1 e B2) mostraram que o etanol obtido é de caráter ácido, já que na matriz da matéria-prima utilizada há presenças de frutas ácidas e semi-ácidas.

Os resultados encontrados nas análises de B1 e B2 foram, respectivamente, pH 3,75 e 3,64, índice de acidez 56,21 e 56,21 mg/L, condutividade 81,4 e $219 \mu \mathrm{S} / \mathrm{cm}$, teor alcoólico 15,60 e 13,04 \%v/v e sólidos totais 0,0543 e 0,1465 mg/L.

A utilização das cascas de frutas ácidas e semi-ácidas pode ser uma boa alternativa para obtenção de bioetanol, visto que, haja cuidados maiores com o controle do pH do meio, durante as reações de hidrólise e fermentação. A viabilidade do processo aplicando a composição da biomassa mista foi positiva e mostrou-se viável para obtenção do bioetanol, tanto devido aos baixos custos, como o impacto socioeconômico, já que agrega valor aos resíduos das frutas que, provavelmente, seriam descartadas.

\section{Agradecimentos}

Ao Centro Universitário Jorge Amado (UNIJORGE) pela cessão da infraestrutura do Laboratório de Química Analítica e Ambiental. Ao técnico de laboratório Joedson Sales, por toda atenção e apoio para realização dos experimentos e análises.

\section{Conflito de interesse}

Os autores declaram não haver conflitos de interesse.

\section{Referências}

Andrade, J. B.; Pereira, P. A. P.; Oliveira, C. S. L. Determination of volatile organic compounds in groundwater by GC: Comparison between headspace and purge and trap. Energy Sources, v. 2, p. 497-504, 1998. https://doi.org/10.1080/00908319808970074

Andrade, P. F. S. Fruticultura: análise da conjuntura agropecuária. Curitiba: Secretaria de Estado da Agricultura e do Abastecimento, 2012.

ANP - Agência Nacional do Petróleo, Gás Natural e Biocombustíveis. Resolução ANP no 19, de 15 abril de 2015. Disponível em: <http://legislacao.anp.gov.br/?path=legislacaoanp/resol-anp/2015/abril\&item=ranp-19-2015>. Acesso em: 29 set. 2019.

Aquarone, E.; Lima, U. A.; Willibaldo, S. Biotecnologia industrial. São Paulo: Edgard Blücher, 2001. v. 3.

Athayde, C. S. Análise dos resíduos gerados pela bananicultura como possível fonte de geração de energia. Belo Horizonte: UFMG, 2014.

Barros, T. D. Milho. Árvore do Conhecimento, Agroecologia, 2010. Disponível em: <https://www.agencia.cnptia.embrapa.br/gestor/agroenergia/arvore/CONT000fbl23vn1 02wx5eo0sawqe3djg2152.html>. Acesso em: 29 set. 2019.

Cerqueira, N.; Ferreira, D.; Almeida, E. P.; Araújo, I. N.; Silva, T. F. H.; Santos, A. G. Caracterização físico-química do biodiesel produzido a partir do óleo extraído da borra de café. Anais do XXIV Congresso Regional dos Estudantes de Engenharia Química, Aracaju, 2019.

Chohan, N. A.; Aruwajoye, G. S. Y.; Sewsynker-Sukai, E. B.; Kana, G. Valorisation of potato peel wastes for bioethanol production using simultaneous saccharification and fermentation: Process optimization and kinetic assessment. Renewable Energy, v. 146, p. 1031-1040, 2020. https://doi.org/10.1016/j.renene.2019.07.042 
Cypriano, D. Z. Biomassa de casca de laranja industrial como fonte de bioetanol e produtos de alto valor agregado. São Paulo: UNICAMP, 2015. (Dissertação de mestrado).

Erman, A. G.; Sar, T.; Seker, G.; Akbas, M. Y. Bioethanol production from fruit processing wastes. Journal of Biotechnology, v. 256, Suppl., p. S41, 2017. https://doi.org/10.1016/ j.jbiotec.2017.06.685

Fernandes, E. R. K.; Afuso, R. K. S.; Scitt, C. C.; Sellin, N.; Souza, O.; Medeiros, S. H. W. Avaliação do potencial para reaproveitamento de resíduos da bananicultura por pirólise. Anais do II Simpósio Internacional sobre Gerenciamento de Resíduos Agropecuários e Agroindustriais, Foz do Iguaçu, 2011.

Fraife Filho, G. A.; Leite, J. B. V.; Ramos, J. V. Maracujá. Brasília: CEPLAC, 2015. Disponível em: <http://www.ceplac.gov.br/radar/maracuja.htm>. Acesso em: 02 dez. 2019.

Grohamann, K.; Cameron, G.; Buslig, B. Fractionation and pretreatment of orange peel by dilute acid hydrolysis. Bioresource Tecnology, v. 54, n. 2, p.129-141, 1995. https://doi.org/10.1016/0960-8524(95)00121-2

Heleno, F. F.; Lima, A. C.; Afonso, R. J. C. F.; Coutrim, M. X. Otimização e validação de métodos analíticos para determinação de BTEX em água utilizando extração por headspace e microextração em fase sólida. Química Nova, v. 33, n. 2, p. 329-336, 2010. https://doi.org/10.1590/S0100-40422010000200019

Joner, G. C.; Battisti, J. F.; Ricci, M. R. Obtenção de etanol a partir da biomassa de frutas. Anais do XXXII Encontro Nacional de Engenharia de Produção, Bento Gonçalves, 2012. p.3-6. Disponível em: <http://www.abepro.org.br/biblioteca/enegep2012_TN_WIC_ 167_970_19677.pdf>. Acesso em: 02 dez. 2019.

Lohrasbi, M.; Pourbafrani, M.; Niklasson, C.; Taherzadeh, M. J. Process design and economic analysis of a citrus waste biorefinery with biofuels and limonene as products. Bioresource Technology, v. 101, n. 19, p. 7382-7388, 2010. https://doi.org/10.1016/ j.biortech.2010.04.078

Martini, A. A.; Neto, J.; Eiras, L.; Bastos, P.; Barbosa, R.; Ulrich, Y. Boletim de monitoramento da qualidade dos combustíveis. Brasília: ANP, 2018. Disponível em: $<$ http://www.anp.gov.br/images/QUALIDADE/BOLETIM/BQ_COMBUSTIVEIS_062018.pdf >. Acesso em: 02 dez. 2019.

Matias, M. F. O.; Oliveira, E. L.; Gertrudes, E.; Magalhães, M. M. A. Use of fibres obtained from the cashew (Anacardium ocidentale, L) and guava (Psidium guayava) fruits for enrichment of food products. Brazilian Archives of Biology and Technology, v. 48, n. sp., p. 143-150, 2005. https://doi.org/10.1590/S1516-89132005000400018

Mendonça, L. M. V. L.; Conceição, A.; Piedade, J.; Carvalho, V. D.; Theodoro, V. C. A. Caracterização da composição química e do rendimento dos resíduos industriais do limão tahiti (Citrus latifolia Tanaka). Ciência e Tecnologia de Alimentos, v. 26, n. 4, p. 870-874, 2006. https://doi.org/10.1590/S0101-20612006000400025

Mohapatra, D.; Mishra, S.; Sutar, N. Banana and its by-product utilisation: An overview. Journal of Scientific \& Industrial Research, v. 69, p. 323-329, 2010.

Moreira, J. R. Obtenção de etanol a partir de material celulósico. In: Rosillo-Cale, F.; Bajay, S. V.; Rothman, H. (Eds.). Uso da biomassa para produção de energia na indústria brasileira. Campinas: UNICAMP, 2005.

Ogeda, T. L.; Petri, D. F. S. Hidrólise enzimática de biomassa. Química Nova, v. 33, n. 7, p. 1549-1558, 2010. https://doi.org/10.1590/S0100-40422010000700023 
Pereira, F. C.; Lima, F. J. S.; Silva, A. O. Uma breve revisão sobre alguns aspectos do álcool combustível veicular e a análise quantitativa de espécies químicas presentes nesta matriz energética. Revista Virtual de Química, v. 8, n. 5, 2016. Disponível em: <http://rvqsub.sbq.org.br/index.php/rvq/article/view/1587>. Acesso em: 29 set. 2019.

Ramiro, C. A. F. Produção e caracterização do biodiesel: estudo e comportamento de antioxidantes. Curitiba: UFPR, 2013.

Schulz, M. A. Produção de bioetanol a partir de rejeitos da bananicultura: polpa e casca de banana. Joinvile: UNIVILLE, 2010.

SEBRAE - Serviço Brasileiro de Apoio às Micro e Pequenas Empresas. Agronegócio: Fruticultura. Boletim da Inteligência. 2015. Disponível em: <http://www.bibliotecas. sebrae.com.br/chronus/ARQUIVOS_CHRONUS/bds/bds.nsf/64ab878c176e5103877bfd3f 92a2a68f/\$File/5791.pdf>. Acesso em: 17 set. 2019.

Silva, C. Avaliação do potencial de uso de resíduos do processamento de frutas na produção de etanol 2G. Maceió: UFAL, 2014.

Simas, M.; Pacca, S. Energia eólica, geração de empregos e desenvolvimento sustentável. Estudos Avançados, v. 27, n. 77, p. 99-115, 2013. https://doi.org/10.1590/S010340142013000100008

Smuga-Kogut, M.; Piskier, T.; Walendzik. B.; Szymanowska-Powałowskac, D. Assesment of wasteland derived biomass for bioethanol production. Electronic Journal of Biotechnology, v. 41, p. 1-8, 2019. https://doi.org/10.1016/j.ejbt.2019.05.001

Souza, O.; Schulz, M. A.; Fischer, G. A. A.; Wagner, T. M.; Sellin, N. Energia alternativa de biomassa: bioetanol a partir da casca e da polpa de banana. Revista Brasileira de Engenharia Agrícola e Ambiental, v. 16, n. 8, p. 915-921, 2012. https://doi.org/10.1590/ S1415-43662012000800015

Vanzella, E. Estudo de propriedades físico-químicas do etanol hidratado com adição de biodiesel para uso em motores de combustão interna Ciclo Otto. Cascavel: Universidade Estadual do Oeste do Paraná, 2015.

Zouhair, F. S.; Benali, A.; Kabbour, M. R.; Kabous, K. E.; El Maadoudi, E. A.; Bouksaim, M.; Essamri, A. Typical characterization of argane pulp of various Moroccan areas: A new biomass for the second generation bioethanol production. Journal of the Saudi Society of Agricultural Sciences, v. 17, n. 3, p. 192-198, 2020. https://doi.org/10.1016/j.jssas.2018. 09.004

Informação da Licença: Este é um artigo Open Access distribuído sob os termos da Licença Creative Commons
Attribution, que permite uso irrestrito, distribuição e reprodução em qualquer meio, desde que a obra original
seja devidamente citada. 